\title{
The bactericidal spectrum and virucidal effects of silver nanoparticles against the pathogens in sericulture
}

\author{
Wenchu $\mathrm{Li}^{1}$, Kapalunenko Volodymyr ${ }^{2}$, Yeyuan Wang ${ }^{1}$, Dimchev Volodymyr ${ }^{2}$ \\ ${ }^{1}$ Department of Sericulture Science, College of Animal Science, South China Agricultural University, Guangzhou, China; \\ liwenchu@scau.edu.cn \\ ${ }^{2}$ Ukrainian State Scientific Research Institute of Nanobiotechnologies and Resource Reservation, Kylv, Ukraine
}

Received 19 May 2013; revised 10 June 2013; accepted 28 June 2013

Copyright (C) 2013 Wenchu Li et al. This is an open access article distributed under the Creative Commons Attribution License, which permits unrestricted use, distribution, and reproduction in any medium, provided the original work is properly cited.

\begin{abstract}
Silver nanoparticles have mainly been studied for their antimicrobial potential against bacteria, but have also proven to be active against several types of viruses, even against pebrine as well. Methods: Petri dishes and transmission electronic microscope were applied to observe silver nanoparticles against bacteria strains and nuclear polyhedral viruses (NPV) and cytoplasmic polyhedral viruses (CPV). For biological test, $10^{8} \mathrm{CFU} / \mathrm{mL}$ NPV with strong pathogenicity, and the NPV samples treated with 1:100 ratio of "Sumerian Silver" for $8 \mathrm{hrs}$ were sprayed on the mulberry leaves, respectively, for silkworm rearing. Conclusion: Silver nanoparticle solution showed a strong bactericidal effect against both $\mathrm{G}^{+}$and $\mathbf{G}^{-}$bacterial pathogenic strains from Bombyx mori and mulberry. Under transmission electronic microscope (TEM), Bacillus sp. Samples showed light particles in the cells when treated with silver nanoparticles, in contrast, untreated samples showed homogeneity contents. Further, NPV particles showed no significant differences between treated and untreated samples, but CPV showed strong effects that almost all CPV were collapsed. For biological test, "Sumerian Silver" treated NPV showed no diseased silkworm but nearly all silkworms were dead with no treatment. It seems like that silver nanoparticles were proved to be more effective against CPV than that of NPV. The significant differences between two antivirus or virucidal mechanism should be greatly aroused the scientific interest.
\end{abstract}

Keywords: Silver Nanoparticles; Bactericidal and Virucidal Agent; Sericulture; Pathogens

\section{INTRODUCTION}

Nanotechnology was rapidly developed after scanning tunneling microscope. Up to now, there are 1317 kinds of nanoscale products all over the world. It increased by $521 \%$ in the year of 2011 compared with that of 2006. The amounts of silver nanoparticles (NPs) products roared up to $55.4 \%$ of 565 special material products in the 30 countries.

The rapid development of nanotechnology made a point of every country in the world. It was one of six research pivots of National Major Developments in Scientific Research Programs of China. It was two of six key technologies in the 21 st century fixed by the EU Industry Committee, which included micro and nanoelectronics and nanotechnology.

Particle size and size distribution are the most important characteristics of nanoparticle systems. Recently they received attention when it was shown that $10 \mathrm{~nm}$ silver nanoparticles were bactericidal, which were promising in light of the growing number of antibiotic resistant bacteria.

Different point of review had been published in the studies on silver nanoparticles act as broad spectrum bacteriaidal agents [1-5]. In the present scenario, nanoscale materials have emerged as novel antiviral agents for the possibilities offered by their unique chemical and physical properties. Silver nanoparticles have mainly been studied for their antimicrobial potential against bacteria, but have also proven to be active against several types of viruses including human imunodeficiency virus, hepatitis B virus, herpes simplex virus, respiratory syn- 
cytial virus, and monkey pox virus [6,7]. Silver nanoparticles have proven to exert antiviral activity against HIV-1 at non-cytotoxic concentrations, but the mechanism underlying their HIV-inhibitory activity has not been not fully elucidated. Lara et al. [8] suggested that silver nanoparticles exert anti-HIV activity at an early stage of viral replication, most likely as a virucidal agent or as an inhibitor of viral entry. Silver nanoparticles bind to gp120 in a manner that prevents CD4-dependent virion binding, fusion, and infectivity, acting as an effective virucidal agent against cell free virus (laboratory strains, clinical isolates, $\mathrm{T}$ and $\mathrm{M}$ tropic strains, and resistant strains) and cell-associated virus. Besides, silver nanoparticles inhibit post-entry stages of the HIV-1 life cycle. Silver nanoparticles are effective virucides as they inactivate HIV particles in a short period of time, exerting their activity at an early stage of viral replication (entry or fusion) and at postentry stages [9].

According to the characters of silver particles, the study initially focused on the bactericidal and antiviral effect on some pathogens to silkworm and mulberry.

\section{MATERIALS}

Bacterial pathogens of silkworm and mulberry: The strains of silkworm pathogens Serratia marcescens, Bacillus sp. Bacillus thuringinsis, Streptococcus aureus, and broad biotic-control agents of Shamin bacterium were kindly provided by Lab of Silkworm Disease in Department of Sericulture Science, College of Animal Science, South China Agricultural University (SCAU); Aecidium mori (Barclay), a fungal disease of mulberry leaves was isolated and purified by Lab of Insect Physiology and Biochemistry from diseased mulberry leaves in Hainan province of South China.

Viral pathogens of silkworm: Nuclear polyhedral virus (NPV) and cytoplasmic polyhedral virus (CPV) were provided by Lab of Silkworm Disease in SCAU.

"Sumerian Silver": A silver nanoparticle solution, was kindly provided by "Nanomaterials and Nanotechnologies" Ltd., Ukraine.

\section{METHODS}

\subsection{Spectrum of Bactericidal Effects}

Method of Petri dish: $5 \mathrm{~mL}$ of solid LB bacterial culture medium was boiled and added to labeled conical flask or test tube. The media were cool down to room temperature, and $5 \%$ volume of cultured bacteria described above was transferred to the flask when it was not freeze. The concentration of bacteria was about $10^{8}$ cells per $\mathrm{mL}$ liquid $\mathrm{LB}$ and blended with medium quickly. The mixed medium and bacterium was poured into Petri dish immediately. When froze media were punched, the
Petri dishes could be used or stored in the refrigerator.

The orifice was injected with samples of "Sumerian Silver" which was diluted previously by $10 \times, 50 \times, 100 \times$, $200 \times$, and $400 \times$, respectively. The positive control was designed as penicillin $\mathrm{K}$ tablet which was dissolved in $0.1 \mathrm{M}$ PBS pH 7.0, with the concentration of $200 \mathrm{U}$ to $4000 \mathrm{U}$ per $\mathrm{mL}$, marked $(+)$; while the negative control was marked (-) in Figure 1 with 0.1 M PBS pH 7.0.

\subsection{Preparation of TEM}

Silver nanoparticles against virus and pebrine diseases of silkworm: The centrifuge pellets of viruses and pebrine disease of silkworm were suspended in the silver nanoparticles "Sumerian Silver" diluted solution with the ratio of 1:10 in $0.1 \mathrm{M}$ PBS $\mathrm{pH} 7.0$, at temperature of $37^{\circ} \mathrm{C}$, for 8 hours. The negative controls were suspended

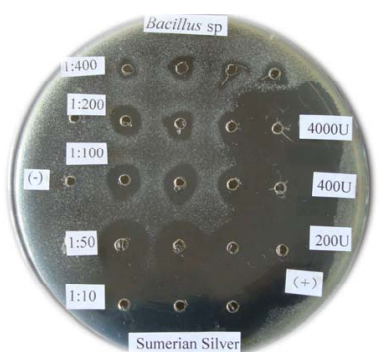

(a)

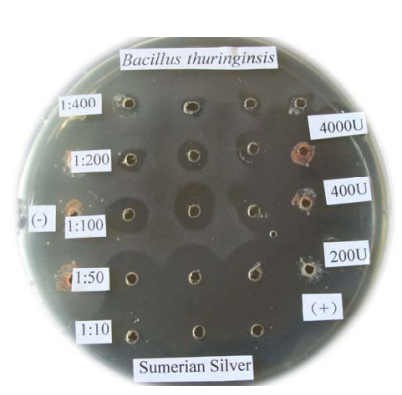

(c)

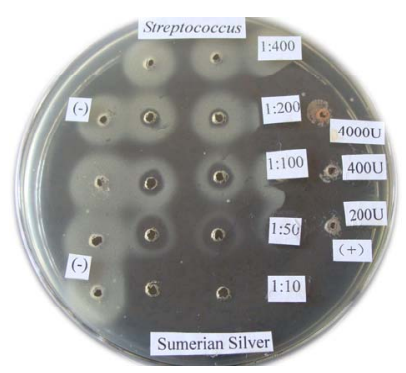

(e)

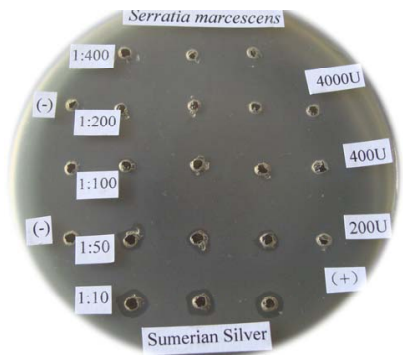

(b)

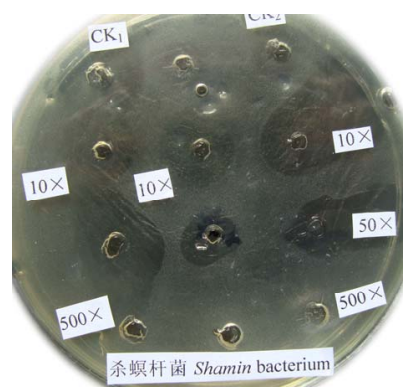

(d)

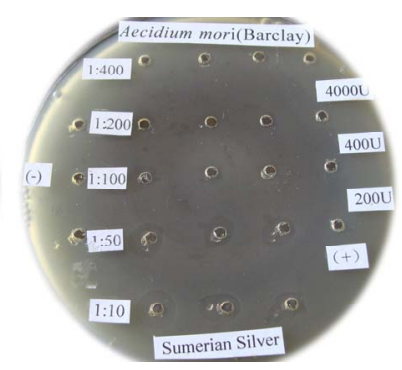

(f)
Figure 1. The bactericidal effects of silver nanoparticles "Sumerian Silver" on different pathogens in sericulture. (a)-(d) present bacterial pathogens of silkworm, Bomyx mori; while F present a fungual pathogen of mulberry. (a) Bacillus spp; (b) Serratia marcescens; (c) Bacillus thuringinsis; (d) shamin bacterium; (e) Streptococcus aureus; (f) Aecidium mori (Barclay). 
in $0.1 \mathrm{M}$ PBS pH 7.0 as the same treatment. The samples were fixed in glutaraldehyde according to the sample's preparation of TEM.

\subsection{Biological Test of "Sumerian Silver" as an Infectants in Sericulture}

NPV with strong pathogenicity was used to test the effect of "Sumerian Silver" on silkworm rearing. The solute was diluted in ratio of 1:10 as storage solution. $2 \times$ $10^{8} \mathrm{NPV} \mathrm{CPU} / \mathrm{mL}$ was treated with work solution of $1: 100$, inoculated at room temperature $\left(25^{\circ} \mathrm{C}\right)$ for $8 \mathrm{hrs}$, and sprayed on the leaves every kilogram for silkworm rearing. For control, it was designed as NPV with no silver nanoparticles treatment, 1:10 "Sumerian Silver" solution and distilled water, respectively.

\section{RESULTS}

\subsection{The Bactericidal Spectrum of Silver Nanoparticles "Sumerian Silver"}

The bactericidal effects of every diluted "Sumerian Silver" were shown in Figure 1. The bacteria on the Petri dish around the orifice could be killed and shows transparent when the antibiotic was injected, otherwise it could grow and not transparent. The diameter of inhibittion zone also could be used to express the bactericidal effect according to Hultmark (1992). The samples of "Sumerian Silver" exhibit extremely bactericidal effects at the concentration of 10 to 50 times dilutions, but it was not obviously observed at the concentration of 400 times dilutions. The results showed that different effects of silver nanoparticles against various bacterial pathogens of sericulture. The bactericidal zone were obviou sly when it against Bacillus spp., Bacillus thuringinsis, shamin bacterium, and Streptococcus aureus even at concentration of 1:400. The less effect was observed on the experiment of silver nanoparticles against fungal pathogen of mulberry, Aecidium mori (Barclay). Further, the least effect were detected when it against Serratia marcescens only at the concentration of 1:10.

\subsection{The Bactericidal Mechanism of Silver Nanoparticles "Sumerian Silver" against Bacterial Pathogens of Silkworm}

Silver nanoparticles "Sumerian Silver" showed strong bactericidal effect on Bacillus spp. as shown in Figure 2. The results showed that the cells of negative control were characteristically uniformed after treated with 0.1 M PBS $\mathrm{pH} 7.0$, while the treatment with $10 \%$ of silver nanoparticles was greatly different. The left picture showed a lot of silver nanoparticles inside the cells and some of bacteria were collapsed after 8 hours.

\subsection{The Effects of Silver Particles "Sumerian Silver" on Viral Diseases of Silkworm}

The viruses of silkworm caused the main portion of lost in commercial cocoon production, although lots of preventative and disinfecting measures were previously carried out before the silkworm rearing. NPV is a kind of baculovirus of silkworm, always broke out in the rural of sericulture zone under high temperature and high relative humidity. No matter how careful the famers take, it seems no way to really prevent its contamination from one farmer to another, from one generation of silkworm to the next. It was wondered whether the farmers disinfected the environments of all silkworm rearing completely and thoroughly.

The experiments of "Sumerian Silver" against viruses could be only observed under electronic microscope. The nuclear polyhedral bodies are enclosed within a membrane, and the rod-like particles could be clearly observed under TEM (Figure 3). Unfortunately, no distinguishable differences could be observed between the negative control (normal NPV) and the samples of "Sumerian Silver" treated NPV.

Surprisingly, cytoplasmic polyhedral viruses (CPV),

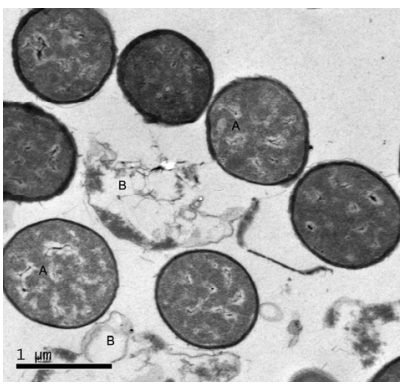

(a)

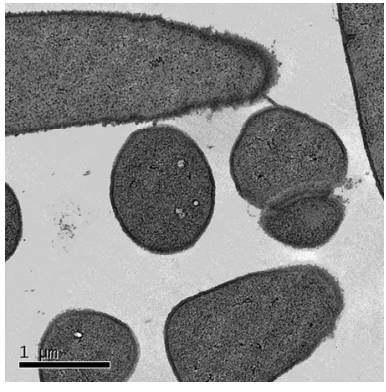

(b)
Figure 2. The bactericidal mechanism of "Sumerian Silver" against Bacillus spp. (a) trested with namoparticle silver showed that some light dense area appeared in the cell of bacteria, while in (b) as control, showed that a unique contents.

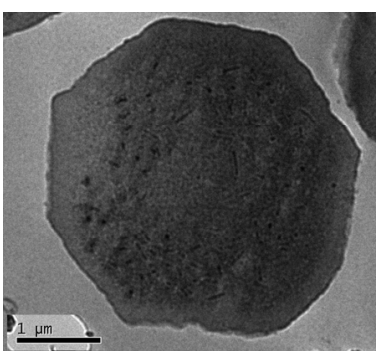

(a)

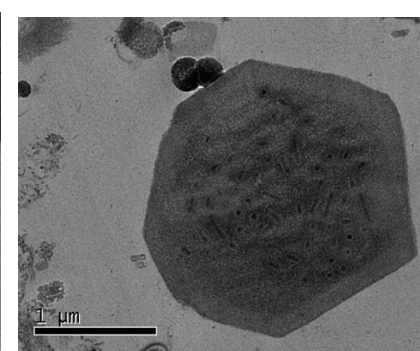

(b)
Figure 3. The effects of "Sumerian Silver" on nuclear polyhedral virus (NPV) of B. mori. (a) Nuclear polyhedral viruses (NPV) of B. mori were treated with $10 \%$ of silver nanoparticles "Sumerian Silver" for 8 hours. (b) The control treated with 0.1 M PBS pH 7.0 for the same conditions. 
another viral disease of silkworm, Bombyx mori, showed different response to "Sumerian Silver" treatment (Figure 4). Nearly all CPV looks like shrunken in the center of the virions. Compared with the negative controls, the border of virions showed no longer smoothly after the treatment with "Sumerian Silver", although the control showed slightly ragged on the border.

\subsection{Biological Test of Sumeiran Silver against NPV}

As expected, the silkworms that reared on silver nanoparticle treated leaves had no diseased silkworms (Figure 5, left). The same results were obtained with that reared on distilled water (figure not shown). In contrast, untreated NPV have strong pathogenity to silkworms (Figure 5, right) that cause nearly all silkworms to death.

\section{DISCUSSION AND CONCLUSIONS}

Over the last decades silver has been engineered into nanoparticles, structures from 1 to $100 \mathrm{~nm}$ in size. Owing to their small size, the total surface area of the nanoparticles is maximized, leading to the highest values of the activity to weight ratio. Due to this property being distinctly different from that of the bulk metal, silver nanoparticles have attracted much attention and have found applications in medicine, biotechnology and bioengineering, electronics, water treatment, catalysis and textile engineering. Furthermore, currently silver nanoparticles are widely used as antibacterial/antifungal agents in a diverse range of consumer products: air sanitizer, sprays, socks, pillows, slippers, respirators, wet wipes, detergents, soaps, shampoos and so on [10].

Recent advances in nanotechnology help in modulation of the size and shape of nanoparticles (NPs) and provide different ways of utilizing the application of nanoparticles in diagnosis and treatment of various diseases [6]. Using the latest technology, Nanomaterials can also be tailored to facilitate their applications in other fields

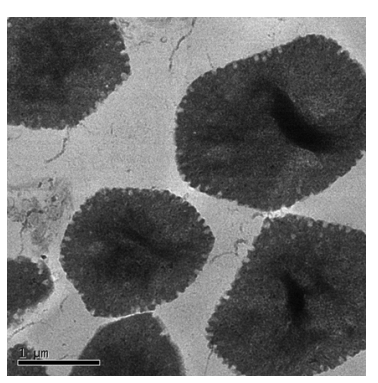

(a)

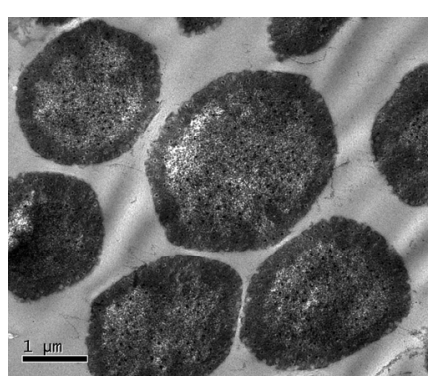

(b)
Figure 4. The effects of "Sumerian Silver" on cytoplasmic polyhedral viruses (CPV) of B. mori. (a) Cytoplasmic polyhedral viruses (CPV) of B. mori were treated with $10 \%$ of silver nanoparticles "Sumerian Silver" for 8 hours; (b) The control treated with $0.1 \mathrm{M}$ PBS $\mathrm{pH} 7.0$ for the same conditions.
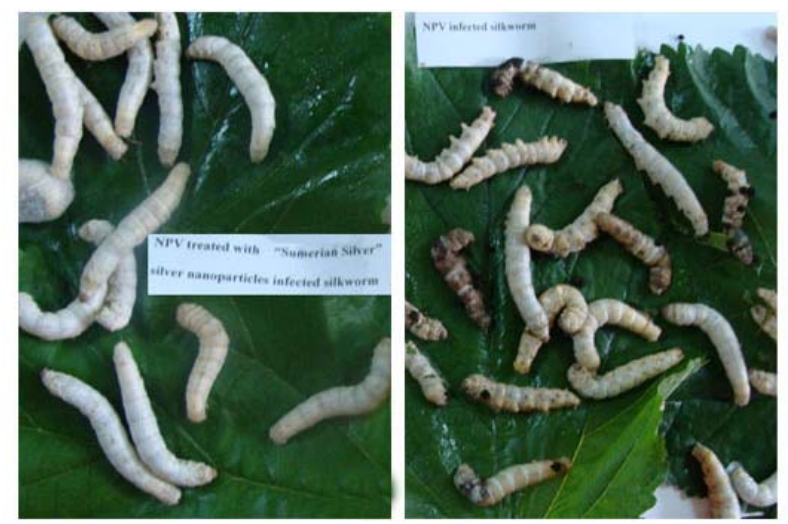

Figure 5. Biological test of nanoparticles "Sumerian Silver". Pathogenic NPV lost pathogenicity when treated with "Sumerian Silver" for $8 \mathrm{hr}$ in the left picture, while no treated NPV caused almost all silkworm diseased to death (in the right picture). The control showed below using 1:10 nanoparticles and distilled water.

such as bioscience and medicine. Silver nanoparticles have received considerable attention for biological applications and recently it was shown that highly concentrated and nonhazardous nanosized silver particles can be easily prepared in a cost-effective manner and possess antimicrobial properties $[11,12]$. The interaction of NPs with microorganisms is an expanding field of research; however, still only a little effort has been made to determine the interaction of metal NPs with organisms and viruses. The conclusion was drawn out from the experiments as follows:

1) The effects of silver nanoparticles had strong effects on bacterial pathogens of silkworm. It was undoubtedly obvious and it could be put into practical commercial use in the rural silkworm rearing.

2) Silver nanoparticles have the excellent effect on viral pathogens of silkworm NPV and CPV. Some evidences were obtained from TEM experiments, but no significant differences could be observed under TEM for NPV, no matter the case of CPV nearly collapsed like a folded sheet. Biological test showed obviously that it had strong effects on eliminating pathogenicity of NPV. The mechanism of virucidal of silver particles might include:

1) Metal nanoparticles, especially the ones produce silver or gold, have proven to exhibit virucidal activity against a broad-spectrum of viruses, and surely reduce viral infectivity of cultured cells. In most cases, a direct interaction between the nanoparticle and the virus surface proteins could be demonstrated or hypothesized.

2) Metal nanoparticles may gain access into the cell and exert their antiviral activity through interactions with the viral genome (DNA or RNA).

3) The intracellular compartment of an infected cell is overcrowded by virally encoded and host cellular factors that are needed to allow viral replication and a proper 
production of progeny virions. The interaction of metal nanoparticles with these factors, which are the key to an efficient viral replication, may also represent a further mechanism of action.

\section{ACKNOWLEDGEMENTS}

The project was granted by Department of Science and Technology of Guangdong Province (2012B050100009). The authors sincerely thank Professor Kaplunenko and Mr. Vladimir Dimchev, in "Nanomaterials and Nanotechnologies" Ltd., Ukraine, for their kindly provided the experimental materials of "Sumerian Silver". The equal thankful was give to Mr. Wangjian, for his warm and quick support every event in the experiment; and Professor Jianrong Lin, for his unselfish guidance; and Mrs. Ya-ling Xu, Mr. Ze-xiong Chen, postgraduate and undergraduate student for their experimental preparations.

\section{REFERENCES}

[1] Lara, H.H,, Garza-Treviño, E.N., Ixtepan-Turrent, L., et al. (2011) Silver nanoparticles are broad-spectrum bactericidal and virucidal compounds. Journal of Nanobiotechnology, 9, 30-38. doi:10.1186/1477-3155-9-30

[2] Lok, C.M., Ho, C.M., Chen, R., et al. (2007) Silver nanoparticles: Partial oxidation and antibacterial activities. Journal of Inorganic Biochemistry, 12, 527-534. doi:10.1007/s00775-007-0208-Z

[3] Qu, F., Xu, H.Y., Xiong, Y.H., et al. (2010) Research progress in bactericidal mechanisms of nano-silver. Food Science, 31, 420-424.

[4] Xiang D.X. and Zheng C.L. (2009) Study of silver-nano- particles on antiviral action. Journal of Dalian Medical University, 31, 716-719.

[5] Chen, M.W., Peng, X.S., Wu, L.N., et al. (2009) Researches and application of silver nanoparticles as antibacterial agent. Chinese Journal of Disinfection, 26, 424-426.

[6] Galdiero, S., Falanga, A., Vitiello, M., Cantisani, M., Marra, V. and Galdiero, M. (2011) Silver nanoparticles as potential antiviral agents. Molecules, 16, 8894-918. doi:10.3390/molecules16108894

[7] Zheng, C.L., Jing, L.X., Zhou, G.T., et al. (2007) The inhibitory effects of silver nanoparticles against NDV. China Poultry, 29, 41-42.

[8] Lara, H.H, Garza-Treviño, E.N., Ixtepan-Turrent, L., et al. (2011) Mode of antiviral action of silver nanoparticles against HIV-1. Journal of Nanobiotechnology, 8, 1-10. doi:10.1186/1477-3155-8-1

[9] Speshock, J.L., Murdock, R.C., Braydich-Stolle, L.K., et al. (2010) Interaction of silver nanoparticles with Tacaribe virus. Journal of Nanobiotechnology, 8, 19-28. doi:10.1186/1477-3155-8-19

[10] Khaydarov, R.R., Khaydarov, R.R., Estrin, Y., et al. (2009) Silver particles. In: Linkov, I. and Steevens, J., Eds., Nanomaterials: Risks and Benefits. Springer Science, 287-297.

[11] Salata, O. (2004) Applications of nanoparticles in biology and medicine. Journal of Nanobiotechnology, 2, 3. doi:10.1186/1477-3155-2-3

[12] Sondi, I. and Salopek-Sondi, B. (2004) Silver nanoparticles as antimicrobial agent: A case study on E. coli as a model for gram-negative bacteria. Journal of Colloid and Interface Science, 275, 177-182. doi:10.1016/j.jcis.2004.02.012 